THEORIA, 2017, 83, 185-205

doi:10.1111/theo.12117

\title{
Can Reasons Be Propositions? Against Dancy's Attack on Propositionalism
}

by

\author{
MATTEO MORGANTI \\ University of Rome 'RomaTRE'
}

and

ATTILA TANYI

University of Liverpool

\begin{abstract}
The topic of this article is the ontology of practical reasons. We draw a critical comparison between two views. According to the first, practical reasons are states of affairs; according to the second, they are propositions. We first isolate and spell out in detail certain objections to the second view that can be found only in embryonic form in the literature - in particular, in the work of Jonathan Dancy. Next, we sketch possible ways in which one might respond to each one of these objections. A careful evaluation of these complaints and responses, we argue, shows that the first view is not as obviously compelling as it is thought by Dancy. Indeed, it turns out that the view that practical reasons are propositions is by no means unworkable and in fact, at least under certain assumptions, explicit considerations can be made in favour of a propositional construal of reasons.
\end{abstract}

Keywords: reasons, propositions, states of affairs, unity of reasons, Jonathan Dancy

\section{Introduction}

REASONS ARE NO DOUBT IMPORTANT. They are important in our everyday life: we customarily refer to reasons when we explain our actions as well as when we try to justify what we plan to do, or what we did. Reasons are also important in contemporary analytic philosophy. In a recent book, Thomas Scanlon (2014, pp. 1-2) points out that reasons have become the focus of philosophical research in at least two ways. First, there is currently more interest in normativity and reasoning spelled out in terms of reasons than in morality. Second, there is more interest in reasons than in motivation - that is, in what morality or prudence demand rather than in what moves one to act in the way one does.

The present article follows this trend and focuses on a somewhat neglected part of the debate: the ontology of practical reasons. That is, the question we are concerned with is what kind of things reasons for action are. When we say that you have a reason to jump off the tracks because the train is coming, what is your reason? That the train is coming, the coming of the train, or perhaps your belief that 
the train is coming? According to Jonathan Dancy (especially in his Practical Reality), the answer is clear: one's reason is the second on the list, namely, the coming of the train. Indeed, Dancy argues in no uncertain terms that all practical reasons must be states of affairs. But why does Dancy say this? Is the view of practical reasons as states of affairs compelling?

Before embarking on a discussion of these questions, it is essential, first of all, to introduce the distinction between normative and motivating practical reasons. Normative practical reasons ${ }^{1}$ are those things that make actions right or wrong and that, consequently, are referred to in evaluating one's actions. Motivating reasons are instead the considerations that figure in explanations that point at the reasons for which the agent acted. These are 'hybrid' in character: for the agent, at the time of acting, these motivating reasons appear as normative reasons. Yet, they need not correspond to normative reasons. $^{2}$

According to Dancy, normative reasons and motivating reasons must be entities of the same type - this is what we will call the 'unity of reasons' thesis, or UR for short. Dancy's master argument for UR consists in his endorsement of the Explanatory Constraint - normative reasons must be capable of playing the role of motivating reasons - and the Normative Constraint - motivating reasons must be able to function as normative reasons (Dancy, 2000, pp. 101-105). The conjunction of these two constraints, Dancy thinks, provides the grounds for believing that motivating reasons and normative reasons are ontologically the same kind of thing. ${ }^{3}$ Although we are sympathetic to the idea that motivating and normative reasons may be identical, hence to UR, two things need to be made clear from the outset: first, UR can be implemented in various ontological frameworks - indeed, while we take no issue with UR, we disagree with Dancy's claims concerning which ontological category normative and motivating reasons must both belong to (in Dancy's case, states of affairs); second, our argument does not crucially rely on UR. In most of the article we discuss Dancy's position on normative reasons, and there UR does not play an argumentative role. Only at the end of the article, when we criticize Dancy's views by making explicit reference to the ontology of motivating reasons, do we make use of UR. But there we will be explicit

1 Sometimes these reasons are called justifying reasons, but we agree with Dancy (2000, p. 107), that the qualifier 'normative' is more appropriate.

2 We are not interested in what Alvarez (2010, p. 36) and Mantel (forthcoming) call explanatory reasons: the reasons that are invoked by agents to explain why they acted in a certain way. Jonathan Dancy, who will be discussed in what follows, has the same focus. See also Hyman (2015, esp. ch. 6) for a good discussion.

3 For a thorough (and, ultimately, sympathetic) recent treatment of UR, see Miller (2008) and Alvarez (2010). Mantel (2014) provides a good critical discussion. 
that our stronger conclusion is conditional on the acceptance of UR, while our weaker claim holds even if UR is dropped.

We can now turn back to our main question: what sort of things are practical reasons? Assuming UR for now, the following appear to be the main candidates: that they are mental states (or facts about mental states), that they are non-mental states of affairs, and that they are propositions. ${ }^{4}$ In this article, we will not take issue with Dancy's outright disposal of the first option, i.e., of what one might call 'psychologism', and will focus on his arguments against the third position, which we label 'propositionalism', and in favour of the second, which we will dub 'statism'.

Of course, as is often the case in philosophy, labels tend to veil a complex reality. In particular, there are many different accounts of all the relevant ontological categories and, to make matters worse, different authors may work with different definitions, and some authors even identify one category with another. Also, although while assuming UR one may talk about 'practical reasons' in a generic way, it is important to keep in mind the distinction between motivating and normative reasons, as different conclusions may be reached with respect to each one of these two categories. Thus, while we will refer to practical reasons (or just reasons) some of the time, we will differentiate between motivating and normative reasons whenever needed, especially in the concluding part of the article.

As for the ontological categories involved, Dancy paints a straightforward picture of the ontology of reasons (as we shall show in the next section). Also, although his account is by no means uncontroversial, it is in many ways an orthodox, mainstream account nonetheless. Thus, it is certainly useful to start a discussion of the ontology of practical reasons with an evaluation of Dancy's specific account. This is what we will do in the rest of the paper.

The remaining part of this article is structured as follows. In the next three sections (2 to 4 ) we summarize Dancy's views and present what we take to be the most sensible reconstructions of his claims against propositionalism. Moreover, we suggest ways in which the propositional theorist could respond to those objections, and critically evaluate these responses. We argue that a careful examination of the emerging dialectic shows that propositionalism and statism are essentially guided by conflicting fundamental visions of what reasons are and what role they serve. That is, contrary to Dancy, propositionalism is not obviously inferior to statism as an account of reasons: instead, it is a theory that should be taken seriously - at least as seriously as statism, at any rate. In section 5, we suggest additional considerations that we take to tip the balance in favour of propositionalism

4 Turri (2009, pp. 491-492) provides extensive bibliography. What we call 'propositionalism' Turri calls 'abstractionism', a difference which is irrelevant for present purposes. See also Alvarez (2016) and Mantel (2014, 2016, forthcoming) for overviews of the relevant literature. 
(at least under the assumption that motivating and normative reasons belong to the same ontological category). In section 6 , we conclude by summarizing the main points of the article.

\section{Dancy's Arguments Against Propositionalism}

As noted, in his 2000 book Practical Reality Dancy aims to argue that normative and motivating reasons are the same kind of thing: states of affairs (hence the title of the book). To do so, using the two constraints we introduced earlier, he first rejects the view according to which normative reasons (what we believe) explain motivating reasons (beliefs) and these, in turn, explain action. After this, he provides arguments against the idea that motivating reasons are beliefs with content, while normative reasons are the contents of such beliefs. Were we to accept such a view, he claims, we would face the following dilemma. If content is understood to be propositional, we get an indefensible account of normative reasons. For, Dancy argues, if they are understood as propositions, normative reasons turn out to be too weak, as it were, to do their job. If, on the other hand, content is understood along statist lines, we end up with an outlandish philosophy of mind. ${ }^{5}$ All this leads Dancy to embrace statism as a form of practical realism encompassing both motivating and normative reasons.

From this short summary, it is clear that a defence of statism is crucial for Dancy not only as a position in the ontology of reasons but also, even more importantly, in the wider context of his overall argumentation. However, his claims against propositionalism do not qualify as proper arguments. At the start of his discussion, Dancy appeals to intuitions. He says:

Intuitively it seems to be not so much propositions as states of affairs that are reasons. It is her being ill that gives me reason to send for the doctor, and this is a state of affairs, something that is part of the world, not a proposition. (Dancy, 2000, p. 114; emphasis added)

But intuitions can hardly carry the weight of a proper argument, at least in this context. Even if we consider them as providing prima facie evidence, in such highly abstract matters as ontology there is good reason not to trust our intuitions concerning individual cases as conclusive or even obviously persuasive. What is more, it is far from clear to us that these intuitions are the sort of universally shared intuitions that Dancy would need to support his position. Exactly the same holds for Dancy's claim that reasons are things that can be the case, not things that can be true, hence propositions are just the "wrong sort of metaphysical beast" to serve as reasons, because there is a clear ontological gulf between

5 However, in Morganti and Tanyi (ms), we argue that this outlandishness charge might put Dancy himself in trouble. 
propositions and states of affairs (Dancy, 2000, pp. 116-117). This, again, simply affirms what needs to be argued for.

As a matter of fact the claims just reported have not been backed up by Dancy (or anyone else) with a detailed discussion. Indeed, it seems to be regarded as not calling for extensive treatment. ${ }^{6}$ Is this because the point Dancy makes is obvious? Is it because the way he makes it is compelling? We believe that the answer to both these questions is negative and that, while common sense may pull towards statism, things are much more complicated once one embarks on a careful philosophical analysis of the issue.

In what follows, we will try to give further substance to these claims of Dancy's, and discuss two more explicit objections to propositionalism that we think can be reconstructed from Dancy's work once one goes beyond mere claims concerning what is intuitively the case. The first (section 3) is what we will call Dancy's Thinness Objection. We will distinguish, and respond to, three interpretations of this objection. The second (section 4) can be dubbed the Representation Objection. With respect to both objections we will suggest, and critically evaluate, several responses. Focusing on those that appear to be the most philosophically promising while also respecting Dancy's core commitments (UR and his general ontological views), we will subsequently move on to a more general critical assessment of statism as opposed to propositionalism, providing explicit arguments in favour of the latter.

\section{The Thinness Objection}

Quoting more fully from the passage mentioned in the previous section, here is what Dancy says:

Now the question is whether on either account (remembering that both accounts are hotly disputed) propositions are the right sort of thing to be good reasons for action. It seems just obvious that they are not. For a class of worlds is hardly the right sort of thing to make an action sensible or right. And an abstract object with a structure that mirrors that of a sentence seems to be no better off. On either understanding, propositions are, as we might say, too thin or insubstantial to be able to make an action wrong. They are the wrong sort of beast. Reasons for action are things like his self-satisfaction, her distress, yesterday's bad weather, and the current state of the dollar. They cannot be abstract objects of the sort that propositions are generally supposed to be. (Dancy, 2000, p. 116; emphasis added)

The two accounts of propositions that Dancy refers to are what he (plausibly) takes to be the two dominant accounts. The first follows Lewis (1986) and takes

6 The only critical reflections on Dancy's arguments that appeared in print are in Lord (2008), Everson (2009) and Hyman (2011). Related discussions can be found in Alvarez (2010) and Hornsby (2008). Alvarez (2016) provides the most recent overview, also including Dancy's specific contributions. 
Table 1. (Practical) reasons

\begin{tabular}{ll}
\hline Propositions & \multicolumn{1}{c}{ States of affairs } \\
\hline Abstract & Concrete \\
Not in the world (not worldly) & In the world (worldly) \\
Capable of being true & Capable of being the case (obtain) \\
Truth-bearers & Truth-makers \\
\hline
\end{tabular}

propositions to be sets or classes of possible worlds, namely, those in which the sentences that express the propositions are true. The second, which follows Frege (1892), regards propositions as abstract objects whose structure mirrors the structure of an assertoric sentence. ${ }^{7}$ Dancy rightly regards propositions on both accounts as abstract and, although more controversially, as not part of the world (Dancy, 2000, pp. 114, 116). ${ }^{8}$ In contrast, states of affairs are entities that obtain or do not obtain (as opposed to propositions that are true or false). As he also puts it, they are capable of being the case (Dancy, 2000, pp. 116-117, 146-147), they are features of the world (Dancy, 2000, pp. 114, 146) or, more specifically, features of the agent's situation. ${ }^{9}$ Although Dancy is concerned with normative reasons in the quoted passage, given that UR is in place, the contrast extends to practical reasons in general and can be summarized as shown in Table 1.

Based on this orthodox contrast between two kinds of entities, Dancy goes on to argue that practical reasons cannot be propositions and must be understood as

7 Dancy notes that there are many competing accounts in the literature, but only focuses on these two. Although he is right that these are to be considered dominant, there is also a third view that requires consideration. It is based on Russell (1903), according to whom propositions are abstract entities built up out of objects, properties and relations. It is, moreover, possible to combine different accounts of propositions in one's theory. George Bealer (1998), for instance, can be interpreted as having something like the Russellian and Fregean account of propositions, respectively, in mind when he distinguishes between connections and thoughts. Gaskin (2009) also has Russellian propositions on the level of reference (which he refers to as 'the world') and Fregean propositions (what Frege called 'Thoughts') on the level of sense. For a good overview of these issues, see McGrath (2014).

8 'More controversially' since, following Wittgenstein, some take the world itself to be abstract. See Gaskin (2009) for a defence of this view.

9 Interestingly, Dancy does not define what states of affairs are. Still, we take him to accept the standard view in the literature: that states of affairs are complexes constituted by objects, properties exemplified by those objects and/or relations between those objects. See Textor (2014) for a good overview. There is also the important question whether Dancy means states of affairs or facts (or both), where, roughly, the former may fail to obtain while the latter may not. While the idea that reasons must be 'worldly entities' plays a crucial role for Dancy, he also says that states of affairs may obtain or fail to obtain. Also, his notion of non-factive explanation suggests that for Dancy statements concerning practical reasons may refer to things that do not obtain. Thus, even though Dancy says at points things like "facts or, better, states of affairs", we will assume that it is states of affairs that should be regarded as reasons in Dancy's view. 
states of affairs. One possible way to interpret this claim is by emphasizing the contrast between the abstractness of propositions and the concreteness of states of affairs in the world. Perhaps propositions cannot be practical reasons because they do not possess the ontological thickness, as it were, to do the sort of things that practical reasons are supposed to do. ${ }^{10}$

Let us call this the Thinness Objection (TO). In the rest of this section, we will consider three possible ways of turning TO into a full-blown argument.

\section{The Thinness Objection as a Metaphysical Objection}

A natural interpretation of the above-quoted passage is that Dancy's suggestion that propositions are unable to serve as practical reasons has to do with the metaphysical nature of propositions, namely, with the fact that they are abstract entities. ${ }^{11}$ Let us, then, try to substantiate Dancy's anti-propositionalist intuition further along this ontological route.

Since TO is formulated with explicit reference to normative reasons, let us focus on this latter category for now. Following Scanlon (2014, p. 31), we can understand "is a reason for" as a four-place relation, $\mathrm{R}(p, x, c, a)$, holding between a consideration $p$, an agent $x$, a set of conditions $c$, and an action or attitude $a$. In particular, $p$ stands in a so-called 'reason relation' - or, as it is often referred to: 'favouring relation' - to $a$. Dancy (e.g., 2004a, ch. 1; 2003, p. 100) clearly accepts this picture of normative reasons; he is what is sometimes called a 'primitivist': he thinks of the favouring relation as primitive, one that we cannot say anything further about. However, he also argues that there is a further normative relation in play between $p$ and a specific monadic normative property of $a$-its oughtness. He calls this relation between reasons and the normative features of actions the 'making-it-the-case relation', or 'ought-making relation'. ${ }^{12}$

10 Another possibility is to stress the representational nature of propositions as truth-bearers (Dancy, 2000, p. 117). This is the basis of the Representation Objection, to be discussed later.

11 In the same place, Dancy specifies that it makes no difference to his argument if one focuses on true propositions, because propositions belong to just one (abstract) entity-type, regardless of whether they are true or false.

12 The following passage is perhaps the clearest (Dancy, 2003, pp. 106-107): "I think of this contributory ought as a monadic feature of an action which is consequent on, or resultant from, some other feature - the 'ought-making' feature, whatever it is. So oughts of this sort are not relations. But for them to be present there must be a certain relation between the ought-making feature and the action. One might suppose that this relation must be the favouring relation. Things are a little delicate here. I am still inclined to say that we are dealing with more than one normative relation. The monadic ought is reached by detaching from the ought-making relation. The train of thought here is 'Feature $F$ ought-makes action A; Feature $F$ is in place; so one ought (so far as that goes) to do action A'. This expresses the idea that the relevant relation is not favouring, but ought-making (or right-making, if you like - so long as 'right' does not mean only morally right). So we can stick to our intuition that favouring is a relation between a feature and an action, and ought-making is a making-the-case relation that holds between a feature and 
Now, the ought-making relation expresses the capability of whatever occupies the place of the reason relatum - so to call it - to affect the other relatum of the relation, i.e., a certain action, by modifying its normative features. This leads to the following interpretation of TO:

1) Propositions belong to the domain of abstract entities;

2) Actions are concrete, worldly items;

3) No abstract entity can affect (the properties of) a concrete entity;

4) Normative reasons must be able to affect (the properties of) actions as concrete entities;

Therefore,

5) No proposition can be a normative reason.

If it is so intended, however, there are possible responses one can formulate to TO. Three of these can be mentioned briefly, mostly for the sake of completeness, as they do not appear particularly powerful.

(i) One may attempt to pull propositions and states of affairs as close to each other as possible: either by making propositions concrete or by rendering states of affairs abstract. The first route might consist in pushing to the extreme the neo-Russellian view of propositions as structured entities, according to which propositions have semantic values as constituents (a view defended by, among others, Salmon, 1986 and Soames, 1987). Let us call this 'radical Russellianism'. Radical Russellianism, however, would require an implausible shift from propositions as logical complexes of (possibly) concrete entities - which would in any case be abstract - to propositions as mereological sums of concrete entities. As for the other approach, one could embrace some version of the identity theory of truth, and claim that (true) propositions are identical to states of affairs (that we usually take to act as truth-makers), and the latter are as abstract as the former (for details, see Gaskin, 2015). However, this second proposal would entail that even in a statist scenario the left-hand side of the ought-making relation is abstract while the right-hand side is concrete. This means that TO would still go through, now besetting statism itself. In view of this, it seems clear that Dancy is likely simply to reject the identity theory of truth.

(ii) One may hold that all properties are abstract entities, thus also denying the supposed concreteness of normative properties as features of actions that take

the (contributory) rightness/oughtness of an action.” It should be added that, as Dancy (2007, pp. 95-96) makes clear, the favouring relation is intrinsically normative and essentially practical (since one of its relata is an action), whereas the ought-making relation is only normative indirectly, due to what it does (that is, endowing an action with rightness/oughtness). 
place in the real world. ${ }^{13}$ This choice might be given further support by endorsing non-cognitivism about the normative, that is, the view that normative sentences do not predicate real properties or, more generally, possess truth-values; or, alternatively, by arguing that reasons relate to action-types rather than tokens, hence to abstract entities. The rationale for this latter claim could be that normative reasons may be invoked when referring to never performed, merely possible actions, and, more generally, that normative as well as motivating reasons typically appear in explanations that aim to have general validity, i.e., that are implicitly or explicitly regarded as being applicable to other agents and their (possible) actions in law-like fashion - thus calling type-type relations into play.

However, one may legitimately resist the idea that, when conceiving of something as a reason, one ipso facto regards it as having general validity. This is, indeed, very likely to be what Dancy would do, based on his moral particularism. More generally, being a non-naturalist realist, Dancy also explicitly opposes all forms of non-cognitivism (see, for instance, Dancy 2006a, esp. sections 6-8). Moreover, he is clearly against the possibility that the relevant actions and properties are anything but real and concrete tokens (cf. Dancy, 2009). ${ }^{14}$

(iii) Another reply to TO might exploit a parallel between practical and epistemic reasons. Epistemic reasons are sometimes taken (Williamson, 2000; Millar, 1993, pp. 55-65) to be propositions that evidentially support, i.e., speak in favour of, our beliefs. This means that the epistemic favouring relation is a normative relation that involves propositions, hence abstract entities, as able to affect parts of the actual, concrete world, and in particular the having of beliefs by particular humans. The same may be said to hold for the practical favouring relation, which relates propositions and the actions of actual agents. On this basis, one could argue that the ought-making relation too can connect propositions to (the properties of) parts of the world (in this case, not the having of beliefs, but rather the carrying out of particular actions). More strongly, parity between epistemic and practical reasons and between favouring and oughtmaking might be said to require a unified ontology of normative reasons as abstract entities. ${ }^{15}$

13 For an overview of the ontology of properties, see Orilia and Swoyer (2016).

14 Also, note that it is by no means obvious that the generalizations involved in the formulation of general laws indicate that the relevant entities are abstract types rather than concrete tokens. In fact, it can reasonably be contended that general claims are only useful tools that hold ceteris paribus, and only particulars are truly relevant. That there are no laws, nor general facts, out there, but only Humean regularities involving specific objects and events is, for example, not an uncommon idea at all in the philosophy of science. See Nanay (2013) for an explicitly particularist view of scientific laws.

15 This might chime particularly well with views of normative reasons that take them to be evidence of what one ought to do (Kearns and Star, 2009). 
However, in this case too things are far from straightforward. First (as done by, e.g., Turri, 2009), one may reject for independent reasons the Williamson-Millar perspective, which is certainly not the common consensus in epistemology. Second, one may point out that propositions evidentially support belief-contents, hence abstract entities, but not the possession of beliefs themselves. Third, especially if s/he agrees with Dancy's moral particularism, the statist could claim that ought-making is a resultance relation (see Dancy, 1993, pp. 73-77; 2004a, pp. 17-28; 2004b, p. 232) expressing dependence between property-tokens, while favouring is a form of supervenience which expresses dependence between property-types. This difference would obviously undermine the parity argument above. Lastly, one could accept the parity intuition but point out that the argument can perfectly be run to reach the opposite conclusion: that is, to argue that, since for independent reasons, provided by TO, propositions cannot stand on the left-hand side of the ought-making relation, we are forced to deny that the favouring relation can accommodate propositions as actors.

(iv) The most promising response to $\mathrm{TO}$ is, we believe, one that takes issue with the crucial claim of inefficacy directly. The key question here is what kind of determination the advocate of TO has in mind. To begin with, suppose implausibly - that it is causation. Propositionalists could maintain that propositions can in fact determine normative properties causally, as they are only abstract in the sense that they lack spatio-temporal location, causal inertness not being necessary for abstractness, at least on some accounts. ${ }^{16}$ More importantly, it is not at all clear that the statist is in any way better off when it comes to alleged causal powers. For, it is far from obvious that states of affairs have causal powers towards the normative domain, except maybe in some particular physicalist settings that cannot, of course, be taken for granted: (particular) actions are certainly physically real, but can the same be said about oughtness or wrongness?

Considering this, it seems legitimate to conclude that the sense of determination relevant here is different from causal determination, and statists had better agree with propositionalists on this point. One might contend that this is obvious, and at no point did Dancy suggest an opposition between statism and propositionalism in terms of causal versus non-causal relations (and corresponding explanations). This is probably the case. But it is also the case that, once causality is explicitly ruled out, the situation becomes much less clear-cut. For instance, one can argue that the ought-making relation is just a form of grounding - a connection between facts based on modal dependence supporting counterfactuals and counterpossibles, which underpins metaphysical explanation. But grounding is

16 For a general discussion of abstractness and its exact definition, see Rosen (2014). Hoffman and Rosenkrantz (1997) is also useful. 
definitely different from causation ${ }^{17}$ and, more generally, is taken to connect (facts involving) various types of entities, with no limitation to concrete entities on both sides. Thus, invoking it might suffice to fill the ontological gap, as it were, between propositionalism and statism.

\section{The Thinness Objection as Having to Do with Value}

Another possible interpretation of TO is suggested by Everson (2009, p. 29), who reads Dancy as pointing to the fact that something can be a normative reason only if it has valuable aspects, that is, if it possesses good (or bad) features, but propositions do not have such a direct connection with value. If this is the right interpretation of Dancy's objection, however, the latter seems to be ineffective. For, Everson himself argues - to our minds correctly - that, even if they are not directly valuable, abstract entities can be connected to valuable aspects of parts of the concrete world. In other words, normative reasons need not be identified with such parts of the world and can simply be in some - perhaps peculiar - connection to them such that those world-bits become relevant for our actions and the related judgements of value. This is a crucial point, which we will say more about in section 4 .

\section{The Thinness Objection as Having to Do with What We Care About}

One may also argue as follows. The way in which we act is determined by what we care about. In sound practical deliberation that leads to action or at least intention, we weigh up what we care about in a way that has, or at least may have, normative power. This means that what we care about and the normative reasons we have should be one and the same thing. But, of course, what we care about are concrete, worldly things, not abstract entities (most of the time, at any rate). Thus, Dancy is right that propositions are the wrong type of things to be normative reasons.

This objection is easiest to understand from the first-person perspective. Suppose that someone was in a traffic accident and suppose I could help her. Why should I? According to propositionalism, the reason would be some abstract object - the true proposition, say, that the person is injured and needs help. However, more intuitively, one would want to say that I should help that person because the person is injured and needs help and this is the thing that I care about and would subsequently refer to in my sound reasoning to this normative conclusion. But this 'thing' is a feature of the situation, a state of affairs (which obtains), not a proposition. ${ }^{18}$

17 If the recently burgeoning literature on ground - see Bliss and Trogdon (2014) for an overview has clarified anything, it is exactly that metaphysical explanations are broader in scope than strictly causal explanations (we say 'strictly' causal because it is an object of discussion whether grounding could be considered a sort of metaphysical causation).

18 Beaulieu (2013, p. 446) explicitly promotes this idea as the best defence of statism. 
We think that this is a forceful interpretation of TO, and one that raises an important point. But we also think it indicates the way propositionalists should go in order to make sense of their view and truly vindicate it as a respectable contender. The basic idea is the same as the one expressed in the previous sub-section, and will be expanded upon in the final part of the article. To be sure, what we care about, like what we deem valuable, is, most of the time, things in the concrete world. But it is still possible that it is something else that allows us to get in touch, as it were, with these worldly things and, based on this, guides our sound deliberations that lead to (normative conclusions about) our actions - thus qualifying as our normative reasons for those actions. In particular, one could claim that the only way for (obtaining) states of affairs to figure in sound reasoning (in fact, in any kind of reasoning) is through propositions; and that it is this crucial mediating role of propositions that undersigns their role as normative reasons. ${ }^{19}$

Before elaborating on this, however, let us discuss the second explicit objection to propositionalism that can be reconstructed from Dancy's writings, a critical assessment of which we take to lead in the same direction. This second objection has to do exactly with the mediating role of propositions just mentioned.

\section{The Representation Objection}

Dancy's second objection against propositionalism is introduced in the following passage:

One consideration that supports this claim is that anything that has a truth value must be in some way representational, since for something to be true things must be as it represents them as being. But no representation can as such be a good reason for anything. The existence of the representation can be, and so can its having other features (such as lewdness, for instance), and so can its being the case that things are as here represented. But all these things are states of affairs and not themselves representations of anything. No representation is the case, and no representation can be a good reason. (Dancy, 2000, p. 117)

Let us call this the Representation Objection (RO).

Like TO, RO does not receive further support in Dancy's book and consequently needs some fleshing out. To start off with, it is helpful to consider the idea of transparency. Representational things are transparent: we always look through them to see what they represent. Now, in the present case, the idea seems

19 Compare Darwall (1983, p. 31): "While a person may cite the weather or the reluctance of her car as a reason for her to take the subway across town, it is because these items figure in what might be said or thought in favour of her taking the subway, such as that it is raining cats and dogs or that her car will not start." Alvarez (2010, p. 42) and Raz (1975, p. 17) also cite a similar thought - that reasons must be capable of being premises in practical reasoning - as a good motivation for endorsing propositionalism. 
to be that when we look for normative reasons we do not stop at propositions, but move directly to the states of affairs they represent. That is, propositions are transparent, hence redundant in a crucial sense, as they fall out during one's quest for normative reasons. In view of this, Dancy's (2000, p. 117) talk of an ontological gulf between things that are capable of being true and things that are capable of being the case can be made further sense of: on the present construal, RO amounts to the claim that propositions cannot be normative reasons because, by necessity, they always and exclusively play the role of mediators between agents and what constitutes a normative reason for them to act in specific ways (i.e., states of affairs).

Indeed, so understood, Dancy's objection is not unprecedented. Dennis Stampe (1987, pp. 337-338, 342-344), for instance, has argued in a similar way against the Davidsonian (Davidson, 1980) idea that desires are normative reasons because they aim at what is of value in the world. Stampe maintains that mental states that aim at value or truth are best understood as reasons per objectum. That is, it is valuable states of the world, not mental states related to them, that provide us with normative reasons to act. The same holds for beliefs: if beliefs, as many claim, aim at the truth, they cannot be normative reasons. It is the states of affairs that they are about and that make them true or false that constitute such reasons. Put in this context, RO would simply carry this line of reasoning to its endpoint: being representational, propositions cannot be normative reasons.

The question is, of course, whether this simply reiterates the statist intuition, or instead represents an argument that effectively puts propositionalists in trouble. As a matter of fact, there seem to be (at least) two responses open to the propositionalist aiming to undermine RO.

(i) One option is to give up the idea that propositions are representational entities. Besides having recourse to the 'radical Russellian' view of propositions as concrete entities that we mentioned (and found implausible) earlier, one may endorse a Fregean view whereby propositions are abstract entities that do not stand in the correspondence relation to anything. ${ }^{20}$ Going one step further, one could endorse the abovementioned identity theory of truth and deny the distinction between truth-makers and truth-bearers. To be sure, these are open possibilities for propositionalists. Yet they are insufficient for a more ambitious defence of propositionalism, aiming to define the view in a way that is compatible with

20 This does not entail that propositions cannot be true or false - the idea is only that they can do without a robust truth-maker. In this connection, consider Skorupski's irrealist cognitivism. Skorupski denies the existence of what he calls the reason-relation (which we referred to earlier to as the favouring relation), but he does not deny its actuality. For him the relation is irreal. As he puts it: "it is certainly true that there are reason relations - there are three, to be exact, and none of them exist" (Skorupski, 2010, p. 428). 
Dancy's specific assumptions. Dancy, as we saw, clearly maintains that there is a strong distinction between truth-makers and truth-bearers, and in particular that there is a significant ontological difference between states of affairs, that are (or can be) the case, and propositions, that can be true or false depending on the way in which they relate to the former. These appear to be plausible claims that propositionalism should attempt to preserve.

(ii) Another response, and indeed our favoured response, to RO appeals to the role reasons play in practical deliberation, and goes as follows: it is obvious that what prompts us to act, or rather, to consider different ways of acting, are (possibly putative) states of affairs; but what we consider, weigh, entertain and face up to in practical reasoning are the propositions that represent those states of affairs; we just do not have a direct connection to states of affairs, and can only get to them through the propositions that represent them, which we can clearly grasp (as Frege, 1918, pointed out). In light of this, the idea emerges that there is no way we can do without propositions: they are indeed transparent, representational entities in the sense above; however, although they are representational, they do not fall out in our quest for reasons - on the contrary, they are exactly the kind of things we look for when we try to individuate our reasons for acting. Putting it more simply, one can argue that RO is not an objection to propositionalism, as that propositions are representational and yet (can) play the role of reasons is exactly what the propositionalist claims.

One may retort that what we are describing above is ordinary practical deliberation that involves motivating reasons only, whereas RO concerns normative reasons. But this would be wrong: the above view of the primary function of normative reasons can also accommodate motivating reasons. This is because there are two kinds of practical deliberation: good (sound) and bad (unsound). While only the former employs normative reasons, it remains the case that both types of deliberation have the same kind of things as their premises. In unsound practical deliberation, one reasons from that $p$ to action (or whatever else one takes the conclusion of reasoning to be) and the same is true of sound deliberation - the only difference being in truth-value, i.e., in the (non-)existence of the $p$ fact. Now, all we need to answer RO is the claim that normative reasons are propositional premises of sound reasoning (i.e., they are belief-contents) $)^{21}$ and one can, although need not, extend this to motivating reasons. This means to

21 This view of reasons bears clear affinity to the so-called reasoning view of reasons (see Setiya, 2014; Way, forthcoming; Silverstein, 2016) - although that view is intended to be an account of normative reasons only. 
hold that motivating reasons too are premises of this sort, albeit they might be premises of unsound reasoning. ${ }^{22}$

Another challenge would be constituted by the claim that, in order to deliberate, we do need to be able to think about reasons, but from this it does not follow that reasons are what we think. ${ }^{23}$ More strongly, employing a distinction with some historical pedigree, ${ }^{24}$ one may contend that reasons are the objects of our thoughts, not their contents; but propositions can only be the contents of our thoughts. How exactly the content/object distinction applies in the present case, however, is far from clear. More importantly, that reasons cannot be identical to the contents of our thoughts and beliefs is exactly the point at issue. And, even if from the fact that we need to think about reasons it does not follow that reasons are the contents of our thoughts, the propositionalist can (and is likely to) insist that there are grounds for thinking that reasons are in fact identical to what we think - even if not necessarily so. ${ }^{25}$

While the foregoing appears sufficient for claiming that, like TO, RO does not represent a lethal objection to propositionalism, it must also be acknowledged that we now seem to have arrived at a crossroads, with two, more or less equally respectable, paths in front of us. For, even if one is not forced to agree with the statist claim that reasons must be states of affairs, and it is possible to say instead that it is the things that (may) represent such items in our mind that do the real work and thus qualify as reasons, no conclusive, or at least clearly compelling, argument seems to be forthcoming either way. After all, what we have painted here are two alternative visions of reasons and what they do. In other words, although we may have found a response both to TO and RO that bears the marks we wanted it to have, ${ }^{26}$ we have not really advanced in a positive way in either

22 This also means that the alternative picture of reasons on which our propositionalism relies also has a natural place for UR. Yet, as we pointed out already, this does not mean that UR plays an essential role in our response to RO. Instead, what happens is that our response puts forward an alternative vision of reasons' role and function and UR may, but need not, drop out of this as a natural consequence.

23 Everson (2009, p. 25) makes this point explicitly. The same idea seems to be expressed by Searle (2001, p. 36).

24 The clearest expression of the distinction is probably in Twardowski (1977).

25 We say more about the role of the content/object distinction in Morganti and Tanyi (ms), where we argue that it should be explicitly endorsed by Dancy. There, however, we also claim that endorsing the distinction is far from an unproblematic move for Dancy and for all statists who agree with his basic assumptions.

26 In particular, we have not given up UR, nor have we modified the ontological picture Dancy has of propositions and states of affairs. There is the question whether our alternative picture of reasons intends to be a constitutive account of reasons (as the reasoning view does; see n. 21). In this case, we would not be respecting Dancy's primitivism and his particularism since they hold that not all items that figure in reasoning are actually reasons (see Dancy, 2004a, ch. 2; cf. Dancy, 2006b, p. 2). However, we do not think that we must be committed to a constitutive reading since all we need to hold to answer RO is that normative reasons are premises of sound reasoning (in fact, perhaps only that they must be able to serve as such premises), not that premises are reasons. 
direction. In the next, final substantial section of the article, we will elaborate on this and try to present additional considerations in favour of propositionalism.

\section{The Challenge of Illusionary Reasons}

As we saw, the main intuition pulling towards statism is that reasons are things that obtain in the world. Yet not all reasons can unquestionably be identified with obtaining states of affairs - especially so in the case of motivating reasons. More specifically, in the statist scenario the agent can falsely believe s/he has a reason to act, i.e., s/he can have a wrong reason, in two ways: either (i) by having a false belief about the obtaining of certain states of affairs in the world (like, for example, when I go to look for a doctor because I think a person is injured, while s/he is perfectly fine and is simply wearing a Halloween mask), or (ii) by having a false belief about whether the relevant relation between a state of affairs and the (properties of the) relevant action obtains (like, for example, when the person I see is actually injured, and because of that, I go to look for a pet jellyfish that has no curative power whatsoever). In the first case, one may speak of an 'illusionary' reason; in the second, of a 'bad' reason.

When it comes to bad reasons, statists and propositionalists are more or less on a par. For, granted that an agent has a false belief regarding whether a normative relation holds between a state of affairs that obtains and (the property of) an action, nothing definite seems to follow from this with respect to whether that state of affairs or, rather, the proposition representing it qualifies as the agent's reason.

Think, however, about reasons that are wrong in the other sense, i.e., illusionary reasons. Consider the case, say, in which I go to the shop to buy beer believing that there is no beer in the fridge, while there is in fact beer in the fridge. The statist, it seems to us, has a hard time making sense of this. For it looks as though s/he can only say that there is in fact no reason for me to go to the shop intending to buy beer, since there is no corresponding (obtaining) state of affairs. However, it seems natural to hold instead that I do have a reason for going to the shop: after all, I felt and thought I had a precise reason to go and buy beer, and indeed a rather good one! The propositionalist, on the other hand, does not incur any such fault. On their theory, wrong reasons (of the illusionary type) are false propositions, while good reasons are true propositions. But, unlike non-obtaining states of affairs, false propositions are not ontologically different from true ones. Both true and false propositions exist, and what distinguishes them from one another is whether they correctly represent the world. In view of this, one may suggest that the amount of unity guaranteed by propositionalism is higher than that provided by statism - with the 
latter having the definitely non-negligible drawback that, as a matter of fact, not all reasons can be identified with entities that are part of the world. Hence, if, as we do in this article following Dancy, UR is assumed to be in place, it is more plausible to think that practical reasons are (in all cases) propositions, rather than that they are (in all cases) states of affairs. ${ }^{27}$

Before closing, though, let us briefly consider other lines of defence that may be available for the statist who, like Dancy, endorses UR.

A first response is that the 'acted for the reason that ...' context is intensional, and therefore carries no referential weight, hence existential commitment, with itself. Even if one allows that 'he acted for the reason that p' can be converted to 'the reason for which he acted was that p', that is, one may be saying something about the agent and nothing else. While we agree with this, it must be stressed that the reasons we are considering for and against statism and propositionalism are not primarily connected to linguistic considerations. The claim is that if we take reason talk to refer to entities external to the agent that ground his/her actions and/or the normative features of the actions s/he does or might do, it is not obvious that these entities ought to be states of affairs, and may in fact be plausibly identified with propositions. ${ }^{28}$

Second, the statist might attempt to save the day by taking on some further metaphysical commitments. Setting aside the identity theory of truth that we discussed earlier, one option would be to adopt a more encompassing notion of reality as including non-existent entities (Parsons, 1980, who explicitly refers to Meinong, 1960) or, analogously, a broader notion of existence that comprises the objects of false beliefs and non-obtaining states of affairs (Plantinga, 1974).

However, this would obviously represent a relevant additional cost for the statist, especially so from Dancy's point of view. Indeed, despite his reference to non-factive explanations and to scenarios in which states of affairs act as reasons in spite of their failure to obtain, Dancy does not believe in the existence of nonobtaining states of affairs. ${ }^{29}$ And this is not surprising, given that his main motivation for subscribing to statism is that reasons must be 'the right sort of beast', i.e., concrete entities.

27 Thus, we are only making a conditional claim to the effect that if UR is assumed, then propositionalism is preferable to statism. Notice, at any rate, that even if one dropped UR, error cases together with the arguments in the previous sections would still make statism weaker than propositionalism in a clear methodological sense, for statists would in any case have to restrict their account to normative reasons only, while propositionalism would also be able to cover motivating reasons.

28 Thanks to an anonymous referee for pressing us on this point.

29 In fact, he rejects White's (1972) idea that beliefs can have non-obtaining but existing states of affairs as contents on the ground that this view is insufficiently realist about true beliefs. See Dancy (2000, pp. 147-148). 
At this point, the statist could argue that false beliefs also have objects, although only in the minimal sense that we can answer the question what they are about, and not in the sense that there is something corresponding to them in the world. ${ }^{30}$ Second, the statist could point out that error cases all concern actions that were done for illusionary reasons, but they are still actions that can be explained (by referring to motivating reasons). This is the abovementioned idea of non-factive explanations. Finally, s/he could contend that the apparently problematic cases are in fact all cases in which reasons appear in the accounts we provide for our actions but, strictly speaking, there are in fact no reasons present out there, neither normative nor motivating (see, e.g., Alvarez, 2010).

However, it seems to us that, whatever one makes of this, the challenge of illusionary reasons is in any case answered more effectively by propositionalism, as the latter does not incur the high price of each of the moves just illustrated - be it in terms of beliefs having merely intentional objects, actions not corresponding to anything counting as the reason for them, or what have you. Moreover, it must be noted here that (with the exception of non-factive explanations) Dancy explicitly argues against the above views.

\section{Summary and Concluding Remarks}

The main aim of this article was to contribute to the debate about the ontology of practical reasons (motivating as well as normative) - in particular, with respect to the dispute between the view (a) that they are states of affairs, and the view (b) that they are propositions - by clarifying the relevant issues and making at least some of the key assumptions and arguments explicit. We focused on the most direct considerations against propositionalism and in favour of statism that can be found in the literature, i.e., Dancy's, which we have tried to expand upon and turn into full-blown arguments. We concluded that a careful consideration of these arguments does not lead towards statism, and instead essentially points to nothing but a clash of fundamental visions of what reasons are and what role they play. Then, on the basis of additional considerations, we concluded with a tentative positive suggestion: namely, that, if anything, in view of the possibility of certain actions done for reasons that are 'illusionary', it is really propositionalism that should be deemed more appealing than statism, at least to the extent that one endorses the idea that motivating and normative reasons must (or are likely to) be

30 Crane (2001) seems to make this point when he says that intentional objects are schematic: they need not be full-blown objects of any kind. 
the same sort of entities, and consequently discards pluralist views of the ontology of practical reasons.

\section{Acknowledgements}

This article has gone through so many stages and revisions that we can hardly remember all those who gave useful feedback on it, and when. Besides the helpful comments we have received from the two referees for Theoria and several others, at any rate, we wish to thank audiences in Alghero, Saarbruecken, Stockholm and Uppsala for commenting on various presentations of this material, as well as Vuko Andric, Richard Gaskin, Susanne Mantel and Stephen McLeod for their valuable remarks, observations and objections. Attila Tanyi's work on the article was supported by a EURIAS Junior Research Fellowship (COFUND Programme - Marie Sklodowska Curie Actions - FP7) at the Collegium Helveticum (University of Zurich/ETH), Zurich. Matteo Morganti's work was supported by the Italian Ministry of University and Research through a FIRB 2012 grant, awarded to the project 'The structure and dynamics of knowledge and cognition' - local unit code F81J12000430001, University of Rome TRE.

\section{References}

Alvarez, M. (2010) Kinds of Reasons: An Essay in the Philosophy of Action. Oxford: Oxford University Press.

Alvarez, M. (2016) "Reasons for Action: Justification, Motivation, Explanation." In E. N. Zalta (ed.), The Stanford Encyclopedia of Philosophy (Summer 2016 Edition), http://plato.stanford.edu/archives/sum2016/entries/reasons-just-vs-expl/.

Bealer, G. (1998) "Propositions." Mind 107: 1-32.

Beaulieu, G. (2013) "Can Explanatory Reasons Be Good Reasons for Action?” Metaphilosophy 44(4): 440-450.

Bliss, R. and Trogdon, K. (2014) "Metaphysical Grounding." In E. N. Zalta (ed.), The Stanford Encyclopedia of Philosophy (Winter 2014 Edition), http://plato.stanford.edu/ archives/win2014/entries/grounding/.

Crane, T. (2001) Elements of Mind. Oxford: Oxford University Press.

Dancy, J. (1993) Moral Reasons. Oxford: Blackwell.

Dancy, J. (2000) Practical Reality. Oxford: Oxford University Press.

Dancy, J. (2003) "What Do Reasons Do?" Southern Journal of Philosophy, Supplementary Volume 61: 95-113.

Dancy, J. (2004a) Ethics Without Principles. Oxford: Oxford University Press.

Dancy, J. (2004b) "On the Importance of Making Things Right." Ratio 17(2): 229-237.

Dancy, J. (2006a) "Nonnaturalism." In D. Copp (ed.), Oxford Handbook of Ethical Theory, pp. 121-145. Oxford: Oxford University Press.

Dancy, J. (2006b) "Reasons, Relevance and Salience: A Response to Hookway." Philosophical Studies 130: 71-79. 
Dancy, J. (2007) "Defending the Right." Journal of Moral Philosophy 4(1): 85-98.

Dancy, J. (2009) "Action in Moral Metaphysics." In C. Sandis (ed.), New Essays in the Explanation of Action, pp. 396-415. London: Palgrave Macmillan.

Darwall, S. (1983) Impartial Reason. Ithaca, NY: Cornell University Press.

Davidson, D. (1980) Essays on Actions and Events. Oxford: Oxford University Press.

Everson, S. (2009) "What Are Reasons for Action?" In C. Sandis, New Essays in the Explanation of Action, pp. 22-48. London: Palgrave Macmillan.

Frege, G. (1892) "Über Sinn und Bedeutung." In M. Textor (ed.), Funktion - Begriff Bedeutung, pp. 23-46. Göttingen: Vandenhoeck und Ruprecht.

Frege, G. (1918) "Der Gedanke. Eine logische Untersuchung." In Beiträge zur Philosophie des deutschen Idealismus 2 (1918/19), S. 58-77.

Gaskin, R. (2009) The Unity of the Proposition. Oxford: Oxford University Press.

Gaskin, R. (2015) "The Identity Theory of Truth.” In E. N. Zalta (ed.), Stanford Encyclopedia of Philosophy (Summer 2015 Edition), http://plato.stanford.edu/archives/spr2016/ entries/truth-identity/.

Hoffman, J., and Rosenkrantz, G. (1997) Substance: Its Nature and Existence. London: Routledge.

Hornsby, J. (2008) “A Disjunctive Conception of Acting for Reasons." In A. Haddock and F. Macpherson (eds.), Disjunctivism: Perception, Action, Knowledge, pp. 244-261. Oxford: Oxford University Press.

Hyman, J. (2011) "Acting for Reasons: Reply to Dancy." Frontiers of Philosophy in China 6: $358-368$.

Hyman, J. (2015) Action, Knowledge and Will. Oxford: Oxford University Press.

Kearns, S. and Star, D. (2009) "Reasons as Evidence." In R. Shafer-Landau (ed.), Oxford Studies in Metaethics, Volume 4, pp. 215-242. Oxford: Oxford University Press.

Lewis, D. (1986) On the Plurality of Worlds. Oxford: Blackwell.

Lord, E. (2008) "Dancy on Acting for the Right Reason." Journal of Ethics and Social Philosophy (September 2008): 1-6.

Mantel, S. (2014) "No Reason for Identity: on the Relation between Motivating and Normative Reasons." Philosophical Explorations 17: 49-62.

Mantel, S. (2016) "How to Be Psychologistic about Motivating but Not about Motivating Reasons." Grazer Philosophische Studien 93: 80-105.

Mantel, S. (forthcoming) "Worldly Reasons: an Ontological Inquiry into Motivating Considerations and Normative Reasons." Pacific Philosophical Quarterly.

McGrath, M. (2014) “Propositions.” In E. N. Zalta (ed.), Stanford Encyclopedia of Philosophy (Spring 2014 Edition), http://plato.stanford.edu/archives/spr2014/entries/ propositions/.

Meinong, A. (1960) "The Theory of Objects." In R. Chisholm (ed.), Realism and the Background of Phenomenology, pp. 76-118. Glencoe, Ill.: Free Press.

Millar, A. (1993) Reasons and Experience. Oxford: Clarendon Press.

Miller, C. B. (2008) "Motivation in Agents." Noûs 42: 222-266.

Morganti, M. and Tanyi, A. (ms) Reasons and Beliefs.

Nanay, B. (2013) "Singularist Semirealism." British Journal for the Philosophy of Science 64: 371-394.

Orilia, F. and Swoyer, C. (2016) "Properties." In E. N. Zalta (ed.), Stanford Encyclopedia of Philosophy (Spring 2016 Edition), http://plato.stanford.edu/archives/spr2016/entries/ properties/. 
Parsons, T. (1980) Non-existent Objects. New Haven: Yale University Press.

Plantinga, A. (1974) The Nature of Necessity. Oxford: Clarendon Press.

Raz, J. (1975) Practical Reason and Norms. Princeton: Princeton University Press.

Rosen, G. (2014) “Abstract Objects.” In E. N. Zalta (ed.), Stanford Encyclopedia of Philosophy (Fall 2014 Edition), http://plato.stanford.edu/archives/fall2014/entries/abstractobjects/.

Russell, B. (1903) Principles of Mathematics. Cambridge: Cambridge University Press.

Salmon, N. (1986) Frege's Puzzle. Cambridge, MA: MIT Press.

Scanlon, T. (2014) Being Realistic About Reasons. New York: Oxford University Press.

Searle, J. (2001) Rationality in Action. Cambridge, MA: MIT Press.

Setrya, K. (2014) "What is a Reason to Act?" Philosophical Studies 167(2): 221-235.

Silverstein, M. (2016) "Reducing Reasons." Journal of Ethics and Social Philosophy 10(1): 1-22.

Skorupski, J. (2010) The Domain of Reasons. Oxford: Oxford University Press.

Soames, S. (1987) "Direct Reference, Propositional Attitudes and Semantic Content." Philosophical Topics 15: 47-87.

Stampe, D. W. (1987) “The Authority of Desire.” Philosophical Review 96: 335-381.

Textor, M. (2014) "States of Affairs." In E. N. Zalta (ed.), Stanford Encyclopedia of Philosophy (Summer 2014 Edition), http://plato.stanford.edu/archives/sum2016/entries/statesof-affairs/.

TurRi, J. (2009) “The Ontology of Epistemic Reasons.” Noûs 43: 490-512.

Twardowski, K. (1977) On the Content and Object of Presentations, transl. R. Grossman. The Hague: Martinus Nijhoff.

Way, J. (forthcoming) "Reasons as Premises of Good Reasoning." Pacific Philosophical Quarterly.

White, A. R. (1972) "What We Believe." In N. Rescher (ed.), Studies in the Philosophy of Mind, pp. 69-84. London: Blackwell.

Williamson, T. (2000) Knowledge and Its Limits. Oxford: Oxford University Press. 